\title{
GENDER BASED VIOLENCE IN PAKISTANI SCHOOLS: INVESTIGATING ATTITUDE OF STUDENTS TOWARDS FAMILY ROLE IN VIOLENCE
}

\author{
JAMIL AHMAD CHITRALI, ${ }^{1}$ \\ ${ }^{1}$ Department of Social Anthropology, University of Peshawar, Pakistan \\ jamilchitrali@upesh.edu.pk
}

\begin{abstract}
The present study examined the attitudes of students in Pakistani schools towards family role in school violence. For this purpose, a case study of selected districts of Khyber Pakhtunkhwa" was carried out in districts Peshawar and Mardan with the sole purpose of eliciting the students' perception on violence. A sample size of 522 respondents (54.6\% boys and $45.4 \%$ girls) was randomly selected on proportional allocation basis from Grade 10 students. Frequency and percentage distribution along with Chi-square test was carried out at uni-variate and bi-variate levels. To understand gender based respondent's perceptions the variable of students attitude towards family role in school violence was restricted to three relevant sub-variables i.e. Students Consult Family in Matters of School Violence, Family Shows Interest in Issues of School Violence, and Friends/Peers are More Important than Family for Consultation in School Violence. Results of the study showed that family interest in school violence was non-significant with physical, psychological, sexual and economic violence. The role of peers/friends had a non-significant relationship with physical, sexual and economic violence.

Keywords: Gender based violence; school violence; role of family; role of peer and friends.
\end{abstract}

1.Introduction :The institution of family plays major role either in the propensity of adolescent to become violent or to become composed and socially acceptable students. It is often the case that family-related issues such as conflict between parents, parents' aggressiveness, separation, divorce etc. may contribute towards the development of aggressiveness and violent behavior among school-going children. Theories regarding relationship between delinquency and disrupted family could be grouped into three categories, viz. life course theories, trauma theories and selection theories (Juby and Farrington, 2001 cited in Ngale, 2009). According to them, 'Life course' theories consider separation not as a discrete event but as a long drawn-out process. These theories also argue that simultaneously multiple stressors are associated with separation. Trauma theories argue that the loss of parenthood is traumatizing event for children because of the simple fact that children's sudden loss of strongly tied relationship (with parent). The third group, i.e. 'Selection theories' argue that disrupted families significantly contribute to delinquency usually because there are pre-existing differences in family income or child rearing methods.

In this regard, Thornberry et al. (1999 cited in Ngale, 2009) assume that children from lone-parent household or from families where divorce or separation has occurred, usually, are more likely to develop a number of 
behavioral problems the most prominent of which is delinquency. However, children coming from two parent families are least likely to develop behavioral problems. This has been substantiated by Wright and Wright (1994 cited in Ngale, 2009), who's research reveal that single-parent families' especially female/motherheaded families, produce delinquent children more than the families with both parents. This is supposedly so because for children from lone-parent households the focus of attention and orientation for socialization shifts towards peers and neighborhood gathering and collectivities. It is, therefore, not surprising that such children usually end up as gang-members as this becomes a much appealing source of belongingness (Muehlenberg, 2002 cited in Ngale, 2009). This is substantiated by Resnick et al. (1997 cited in Windham, 2005) survey of more than 12000 teenagers, which found that sense of close connectedness to parents, friends and school protected them from a number of violent and risky behavior. In another study on assessment and comparison of cognitive development of children coming from single-parent households and intact families, Heritage Foundation (Brief No. 35:01), utilized Peabody Vocabulary Test (PPVT1), which measures cognitive development of children. The result showed that children living with single-mother or single mother and cohabiting partners demonstrably fared worse than children living in married and intact families.

Another pertinent point to the above analysis is the type of attention or socialization that youngster receive from parents and other social groups to which they belong. According to their Structural-Marxist theory regarding the production of delinquency Colvin and Pauly (1983 cited in Kramer, 2000) argue that economic reproduction processes coupled with social reproduction processes in workplace, peer group, school and family determine the intensity, type and frequency of a given delinquent behavior. Specifically they argue that "the more coercive the control relations encountered in these various socialization contexts tend to be, the more negative or alienated will be the individual's ideological bond and the more likely is the individual to engage in serious, patterned delinquency' (Colvin and Pauly, 1983: 515 cited in Kramer, 2000: 132). With respect to adolescents, then, we could cite Pfohl (1994 cited in Kramer, 2000) who persuasively argue that perception of powerless and alienation and feelings of frustration - whether due to social structure or economic structure - among adolescents develops into violent behavior which works as a means for reasserting their power and control in their lives (Pfohl, 1994 cited in Kramer, 2000).

It is accepted that schools in any society will reflect the outside culture in terms of violence or security, and that they are also likely to have a reinforcing effects on this culture (Davies, 2004, Harber, 2004). However, some schools may be atypical, being less or more violent than would be assumed from looking at rates of violence or criminality in wider society (Astor, Benbenishty, \& Estrada, 2009). Schools may be able to act relatively independently and offer an alternative form of socialization. It is important to identify how they do this, yet to make rigorous connections between school ethos and (non) violence requires frameworks for linkage and comparison. This study aims to establish comparative indicators, basically qualitative in nature with space for future research to build on the findings of this study for quantitative research on the subject and to have such framework established for comparison. It also aims to provide systematic trends of violence indicators which would enable establish tools for future researches to analyze trends over time. Such trend analysis would also facilitate scrutiny of what preventive measures have sustainable impact.

There are myriad definitions of violence, and there are a considerable number of different typologies. Salmi(Salmi, Smolej, \& Kivivuori, 2007), for example, distinguishes four types, direct violence (murder, harm, slavery); indirect violence or violence by omission (the failure to provide protection); repressive violence (human rights violations such as freedom of religion) and alienating violence (racism, ostracism, living in fear). Dubet (Dubet, 2003) on the other hand uses characterizations which relate more to the causation of juvenile violence: 'normal' or tolerated in traditional settings; 'territorial' to create microsocieties; 'utilitarian' to reduce tension of school failure; and 'revolt' or insurgency motivated by feelings of domination or exclusion. Charlot and Emin (1997) are cited to distinguish three levels of school violence(Mallet \& Paty, 1999) that includes Firstly, the violence itself (injury, sexual violence, crime,

1The data is taken from the source: (Wendy Manning and Kathleen Lamb, "Adolescent WellBeing in Cohabitating, Married, and Single-Parent Families," Journal of Marriage and Family, Vol. 65 (November 2003), pp. 876-893. 
vandalism etc.) which would relate to Salmi's 'direct violence; secondly, incivilities (humiliation, lack of respect); and thirdly, symbolic and institutional violence (irrelevant schooling, power relations between teachers and students). Social analysts such as Bourdieu (2001) would add structural violence that is the violence perpetrated by dominant groups in society based on social structures such as race, gender, social class or religion, by which certain groups are systematically denied opportunities or rights. In recent years, a concern is increasing about violent extremism, and what sort of contribution educational institutions make to its prevention or otherwise (S. E. Evans, Davies, \& DiLillo, 2008).

This study is considering four categories of violence in schools: Physical (corporal punishment, fights, attacks on students or teachers etc.), Socio-Psychological Violence (verbal aggression, humiliation, denial of rights to dignity, cyber-bullying); Sexual Violence and Economic Violence. While it would be easier just to look at physical violence, this would ignore the myriad ways in which students and teachers experience harm in their school life. On the other hand, if the intention is to generate indicators, which are helpful to schools their daily practice, the study cannot enter the complex field of how structural violence is manifested in education systems (access to schools, drop-out rates etc.). These are already tackled in the 'Global Monitoring Reports on Education for All' and on the achievement of the 'Millennium Development Goals'. Clearly, if racism or gender abuse is experienced, as related to wider structures of discrimination or violence, this will emerge anyway in the categories designed in this research for violence. We take the boundary to be 'the intention to do harm'. Article 19 on the Convention of the Rights of the Child conceptualizes violence as 'all forms of physical or mental violence, injury or abuse, neglect or negligent treatment, maltreatment or exploitation, including sexual abuse' and this would form a starting point as it is internationally agreed. The World Report on Violence and Health (Krug, Mercy, Dahlberg, \& Zwi, 2002), defines violence as 'the intentional use of physical force or power, threatened or actual, against a child, by an individual or group, that either results in or has a high likelihood of resulting in actual or potential harm to the child's health, survival, development or dignity' (Pinheiro \& Unies, 2006). Clearly, our definitions of violence would have to include violence against adults as well as children, but the notions of the intentional use of force or power and doing harm to the person, either physically or mentally, are the key signifiers.

Evolutionary perspectives based on successful functional and adoptive strategy of action as envisaged in evolutionary theory of violence needs more consideration to be highlighted while attempting to work on any issue related to violence (Eisner, 2009). The evolutionary perspective categorizes violence as deflected in different categories such as violence in non-state society based on rituals, interpersonal criminal violence based on assault, punishment inflicted by parents or state, organized private violence under a particular organization, legitimate and illegitimate state violence (assassination and execution) organized political violence such as civil war and rights. Violence could not be confined to either reason with exception to moral actions, rather it is situational based activity and have strong roots in moral interpretation as explained by Eisner (Karstedt \& Eisner, 2009). However social conditions such as integration and segregation along with individual developmental trajectories could not be ignored as a cause of violent behavior (Wikstrom \& Treiber, 2009). The argument of associating violent extremism with madrassa education of Pakistan is largely rejected in current research discourse (Looney, 2004);(Ladbury \& Khan, 2008; Yusuf, 2009) as it contribute not more than $1 \%$ of the total student enrollment in the education system of Pakistan and the public and private sector school students have shown comparatively high level of support for violence in comparative researches (Khan, 2008).

In this scenario the existing study is very much important for Pakistan, being the only two southern countries studied by Plan International (Pereznieto et al., 2009) to have no laws to protect school-aged children from all forms of violence. This may represent different dimensions of school violence, for example, with the use of corporal punishment in school, with different histories of violence and conflicts among peers in school settings, and different sorts of inequalities which might trigger out frustration and violence due to various expected variable to be recorded. There is no study to date carried out in terms of analyzing the institutional structure of schools where violence is produced/experienced and the variation it has based on nature of school i.e. government schools for girls; boys; and or private schools with co-education. The United Nation Development Program (UNDP) through 'Peace and Development Program' intended to have outputs that were aimed towards improving community infrastructure and reducing 'vulnerability of youth towards extremism. According to the report for the first quarter of the year 2011, the program has helped rehabilitation 
of schools in Khyber Pakhtunkhwa Province. However, both locally and globally very few studies exist that have documented various forms of violence in schools(Pereznieto et al., 2009).

Above review comprehensively spills over the importance upon the issue at hand with its application to different societies across the globe on the basis of situational perspectives. Pakistan is a developing country where a number of policies not only framed but implemented also by the government in educational sectors with focus on many dimensions including punishment. Despite all these efforts the literacy rate is still very low which has led to the consistent existence of ignorance. Keeping into these grim realities a number of NGOs has landed into the arena for the purpose of addressing the issue. The main reason associated to this effect is the enhancement in literacy rate and containment of violence existing in all shapes and manifestations (SAHIL, 2008). This study specifically explores the attitudes of students about the role of family school violence in two districts of Khyber Pakhtunkhwa, Pakistan.

2.Research objective: The main research objective of this study is to examine the attitudes of students regarding the role of family in school violence.

3.Literature review: Research on the relationship between family-structure and delinquency demonstrate clearly that the institution of family primarily aims towards conformity among youth by monitoring and disciplining them and by developing close parent-child attachment (Featherstone and Monserud, 2006 as cited in Fry, 2010). On the contrary, if there occurs a structural change in the family, e.g. divorce, single-parent homes, lone-mother working for long hours outside home, adversely affect child-rearing practices, it leads to juvenile delinquency (Fry, 2010). The impact of divorce could be multiple and sometimes serious. For example, Beaulieu and Messner (2010 cited in Fry, 2010) research regarding the effects of divorce on homicide rates, found that children suffer emotionally, academically, and even physically as a result of their parents' divorce; there are marked differences with respect to academic achievements and tendency towards violence between children whose parents divorce and children living in intact two-parent families. As pointed out by Fry (2010) divorce is just one of the many forms of disruptions in family that could diminish the pattern of socialization and normal personality development of youngsters. Thus even if no divorce occurs but there are issues such as parental conflict, economic distress and meager parenting practices these would compromise children's psychological, social and economic well-being (Furstenberg and Teitler, 1994 cited in Fry, 2010).

Children coming from single-parent family and those coming from intact family (where both the biological parents/partners are living together) are usually observed to exhibit differences in terms of sociability, achievement and aspirations. According to the findings of Breivik et al. (2009 cited in Fry, 2010) and a number of other scholars (e.g. Mandara and Murray 2009; Aston and McLahan, 1994; Downey and Powell, 1993; Wu, 1996 cited in Fry, 2010) have found that children from single-parent households have higher propensity towards delinquent behavior. On the contrary, children in intact families almost always exhibit greater academic achievement and overall educational attainment. Similarly, they are seldom seen to behave problematically in school. Part of the reason is that their parents tend be involved in their school activities and have high expectations for them (The Heritage Foundation, Brief No. 35: 01). Whether we take the issue of socialization in single-parent families or in intact families, certain extra-familial factors are pertinent to look for with respect to the emergence and sustenance of violent behavior among children. For example, a very well-known fact is that parents engaged in blue-collar work and doing menial jobs where they are strictly monitored, have been observed to have harsh and/or inconsistent parenting styles. Children in such environment gradually develop alienation from parents culminating possibly in serious behavioral problems (Colvin and Pauly, 1983 cited in Fry, 2010). According to Vander Ven et al. (2001), working mothers have negative effect on children's socialization and possible incorporation into delinquency. However, this is usually the case in urban contexts but not in rural contexts. With respect to urban areas, Vander Ven et al. (2002 cited in Fry, 2010) argues that children whose mothers are working spend more time with peer groups; the pattern of orientation and learning shifts towards peers which in most of the cases lead to delinquent behavior and violence. 
In everyday discourse we do not argue about the assumption that educational institution is one of the main agent of harnessing human capabilities and hence the achievement of just, equitable and flourishing society (Sen, 1999). This should be so because healthy and educated population can participate in and contribute towards individual and collective well-being. Assumedly, education contributes to development in at least three ways. Through the ability to read and write, communication and acquisition of knowledge, education directly brings improvement in a human being's well-being. Secondly, it indirectly improves well-being by increasing productivity of an individual. Finally, education indirectly contributes towards well-being by bringing improvement in earnings of an individual (Sen, 1999). However, it is noted that the institution of education, though assumed to be homogeneously benign, does not always cater for the needs of all students in equal terms. Whether we discuss developed countries or underdeveloped countries participation in educational institution does not bring universally similar and equal psycho-social benefits to pupils. The social space of school is usually wrought with inequality of gender, ethnicity, class, language and other forms of identity. Popular belief is that education gives freedom of thought and action but in reality schools may be the places where some students may learn "... their place of un-freedom" (Unterhalter, 2003). Instead of winning freedom students may learn their un-freedom and violence especially when it comes to gender-based violence. It is not unlikely that years of schooling may translate into participation and interaction in environment wrought with gender-based violence, resulting in poor health, psychological upbringing and socialization into culture of violence.

Schools occupy strategic position in the development effects on children they could be agents of violence as well as violence-prevention given the fact that right from enrolment early in life until school leaving, a student approximately lives half of his/her life in school (Sullivan \& Bash, 1967). Should it be surprising to see children becoming violent, when on daily basis and for a number of years they are made to sit for hours, cramming notes in frontal teaching methods in an authoritarian environment? Thus the thesis that rising level of pupil-to-pupil and teacher-to-pupil violence in schools is related to compulsory education seems plausible. This is because, being subject to controlled environment from early childhood to the age of sixteen or eighteen develops considerable amount of frustration (Eacute \& Esteve, 2000), which cannot be undone without being externalized by the students in the form of violent reactions in children (Adams, 1991; Harber, 1998), loss of creativity (Harber, 2002: 11), and increased drop out and repetition rates (Green, 1998: 155). This might occur because an individual's sense of coherence is composed of three elements, viz. comprehensibility, manageability and meaningfulness (Antonovsky, 1987). In line with this Bowen et al. (1998) cited in (Lovegrove, Henry, \& Slater, 2012) with respect to school children explained these elements to be (a) learner's self-perception of feelings, (b) meeting the demands and challenges of education and (c) being engaged in school. It might be true that in 20th century, family and religion have lost their ground to schools as primary means for socialization of children (Omaji, 1992). But is this means of socialization safe and sound for children? We might be right in our belief that school is powerful means for value transmission, reformation and change (Griffin, 1978; A. W. Jones, 1975) through its role in raising critical thinking abilities and innovation in children (Omaji, 1992; Stromquist, 2007) but they also operate as mirror of society (Ngakane, Muthukrishna, \& Ngcobo, 2012). Therefore, we must clearly understand, Tunley (1962) warns, that school is agency for violent behavior and attitudes(Tunley, 1962).

From individual-level perspective, individuals in pre-literate societies - quite contrary to the classic myth of barbarism and savagery - enjoyed considerably liberal environment. Yet school based violence has emerged as a bigger issue in developing countries than in developed countries. Complaining about authoritarian environment in schools in South Africa, Harber and Mncube (2011) contend that the European model of state formation, modernization and control got diffused to the colonies. According to (Altbach \& Kelly, 1978) see also (Mynard, Joseph, \& Alexander, 2000) the effective functioning of colonial administration needed slavish people. Hence, a cost-effective method of mass education through missionary schools was devised wherein learners were taught the superiority of colonial culture thereby paving way for the production of politically docile and controlled environment. Even if we take this as mere exaggeration that hinges on externalization of violence-related problems to extra-societal factors in developing countries, there are still other factors that led to the introduction of violence in mass-education schools in the colonies. The factor of belief system of colonial master seems to be the most plausible reason. For instance, according to Parker-Jenkins (1999: 6), Victorian Britain's belief in physical chastisement translated into physical disciplining of children which was 
upheld by law courts 2 as teachers 'right. It should not be mere coincidence that corporal punishment, verbal abuse and other forms of violence got introduced in India, Pakistan, and Bangladesh, which were formerly a single colony of England. The persistence of authoritarian mode of administration - including educational administration - in post-colonial era now called violation of human rights (Harber and Mncube, 2011) has had historical roots in colonial administration. The right to discipline a child is resentfully institutionalized in authoritarian form of teaching. This should be so because in many cultures, particular of South Asia, teachers are socially valued as most respectable. Almost every teacher performs his/her role with this ideological backdrop in mind and every student succumbs to teachers' will under its influence. Resultantly, boundaries between the notion of a right and a duty gets blurred in that teachers' cognitively focus on extracting respect out of children (the right) instead of imparting skills to them as their main job (Tamutiene, 2008).

In order to have disciplined and morally correct citizens, schooling system usually adopt teacher-administered 'corrective' mechanisms - corporal punishment, beating, bullying harassment etc. (Grosvenor, Lawn, \& Rousmaniere, 2000). School teachers and administrators could operate both as perpetrators and victims of violence but their documented role is usually of perpetrators. Likewise, boys and girls are both the perpetrators of violence but boys predominantly are more the perpetrators. Violence exists in various forms such as physical injury (assault) (Antonowicz, 2010), abuse of power (bullying) (Piotrowski \& Hoot, 2008), sexual harassment (Jones et al., 2008). Diverse typologies of violence in schools could be developed but mostly literature group school violence into three categories of bullying, sexual abuse and corporal punishment (Harper 2010: vi; Plan, 2008: 7). Schooling as violence and violence in schools has become a pressing issue in both developed and developing countries and there is need to undertake methodologically sound researches to prevent schools from becoming violent (Kimmel \& Mahler, 2003).Current research warrants it.

The culture of using corporal punishment for disciplining children in schools is a global problem. Despite the fact that corporal punishment is just one of the many ways of disciplining children (Sanderson, 2003) it is practiced at large as the only way for behavior correction. Two reasons are often cited as rationale for its practice. Firstly, it is legitimated on the grounds that all children of the same age are similar in their personality attributes and therefore they should be subjected to similar types of discipline strategies (Harber, 2002: 10). Secondly, it is considered necessary and perhaps essential for disciplining (Plan, 2008: 48; Dunne, Humphrey \& Leach, 2006) which besides tantamount to a legitimized form of authority (Harber, 2002) also paves way for other forms of violence in schools. Perhaps, that is the reason why despite UNVAC's 2009 call for ban on corporal punishment in schools 90 out of 197 countries still allow its use (Plan, 2008). Corporal punishment is legal in both rich and poor societies such as France, Korea, Australia, a number of states in US, Pakistan and Cambodia (Balaya and Debarbieux, 2008). Even where legal, strict guidelines exists for administering corporal punishment but they are seldom abided by and students are reportedly slapped, hit, or kicked (Youssef et al., 1998; Chianu, 2000; HRW, 1999). This shows the formal and informal institutional fabric of societies where in structure of violence is deeply entrenched. A more ironic fact is that in many countries despite its illegality, corporal punishment is practiced (Durrant, 2005). Part of the reason is that many countries; especially Asian, corporal punishment is practiced under the influence of social value of respecting elders. Children would have to keep silent even if a teacher is using it indiscriminately, which according to Plan (2008) perpetuates an intergenerational cycle of violence and support for children's violent behavior. It is due to such social values that teachers would denounce media reports and would hardly inform authorities regarding such practice (Dubet, 2003). Its practice paves the way for children's socialization into violence by orienting towards the notion that violence should be used when one does not agree with others (De Wet, 2007; White, 2007; Plan, 2008; Gulbenkian Foundation, 1995). Research also demonstrates that the more it is practiced the more a child would exhibit only overt conformity but in reality he/she would be inculcated with feelings of aggression and tendency towards physical aggression against other children (Naz et al., 2011; Gulbenkian Foundation, 1995). And thus the socially created environment of violence triggers a general tendency towards authoritarian attitudes and violence (Harber and Mncube, 2011). The preceding analysis may suggest school environment as the sole contributor to gender based violence at school among adolescents. However, though central in themselves, schools are part of the agents of socialization of children

\footnotetext{
${ }^{2}$ It was as late as 1986 that corporal punishment was finally banned in England (Parker-Jenkins, 1999: 6).
} 
and adolescents. Students' background factors such as ethnicity, economic status, religious orientation, type of family etc. are also central to the way the process of violence gets shaped and formed in schools.

Current research shows that a multitude of individual, social, economic and contextual factors may be contributing towards adolescent students' propensity to violence and criminal behavior at and around school (Chandras, 1999 cited in Windham et al. 2005). Research on relationship between poverty and delinquency and violence is, perhaps, one of the oldest areas of academic scholarship. The age-old maxim of poverty leading to violence holds no ground anymore in the sense that showing direct and explicit causal relationship between poverty and violence is seriously difficult. Obviously, there are a large number of intervening variables affecting violence among the power. However, research does clearly substantiate that the intensity and/or frequency of violence and is relatively higher in neighborhoods with low socio-economic status than the high socio-economic status neighborhoods; inversely, with respect to positive personality traits such as intelligence, language acquisition, critical thinking etc. children from higher socio-economic status excel from children from low socio-economic status. For instance, Hart and Risely (1995 cited in Dillon, 2012), in their longitudinal study clearly identified major achievement gaps between children from low socio-economic status (SES) and those from higher SES. Poor SES makes its mark right from the age of 3 such that children from low SES are low on developmental path than children from higher SES. Similarly, in its study of children's educational achievement in the US, the National Centre for Children in Poverty (2006 Cited in Dillon, 2012) found that among those children involved in the welfare system, $50 \%$ suffered from some form of mental health concern. More specifically, of those between the age of 6 and 17 from low SES, 21\% had mental health problems. A more vivid fact is that from among those who suffered from mental illness, $57 \%$ belonged to households who were at or below the official poverty line (National Centre for Children in Poverty, 2006 cited in Dillon, 2012: 06). In terms of additional consequences and impacts of poverty, Bringewatt and Gershoff (2010 cited in Dillon, 2012) state that such children being exposed to violence, emotional stress, parental distress and parental depression are resultantly vulnerable to behavioral problems and mental health issues. These findings are also supported by Currie (1998 cited in Kramer, 2000) who argues that there is overwhelming evidence regarding the role of inequality, social exclusion and extreme poverty in influencing social experiences to violence and crime. This is so because such phenomena seriously impact on smooth functioning of the institution of family and close-in community. Whether the case in point is a small neighborhood in a city or a country poverty and inequality does lead to higher level of violence (Gartner, 1990 cited in Kramer, 2000). Moreover, within the deprived neighborhoods or regions, it is the chronically and persistently deprived children who are at risk of involving in violence and crime (Werner and Smith, 1992 cited in Kramer, 2000).

If we ask as to how gender influences orientation towards and perpetuation of violence in various social contexts, (Parker \& Gagnon, 1995) suggest that researcher(s) should focus on the distribution of power between males and females in specific contexts, i.e. research should aim at understanding how power relations develop and get sustained in specific social and cultural settings (Vance, 1984). Cultural norms and values give birth to specific forms or regimes gender inequality which could pave way for the establishment and perpetuation of gender based violence (Parker, Barbosa, \& Aggleton, 2000). School environment usually give legitimacy to teachers' authority: whether it is regulation or control of students' behavior, teachers determine 'appropriate' behavior for students as gender-differentiated beings. This is done through a system of reward, punishment, sanctions, time-distribution in class and attention span in class. The gender regime gets established and signified in two ways: firstly, by ignoring certain behavior traits and by punishing other acts. For instance, teacher may establish his/her authority by insisting on certain forms of address ('Sir' or 'Madam') from students but boys fight among themselves or intimidate girls, it would be dismissed as merely 'teasing' or as 'boys will be boys'. Through such forms of interaction, teachers help in normalizing certain behavior traits of students, thus contributing towards gender differentiation and a hierarchy in which males dominate (Jackson \& Newman, 2004).

The feminine and masculine identities also get entrenched through the hidden curricula and students' informal learning. For example, girls in many Asian schools are required to do cleaning while boys are required to do digging. Activities such as these are indicators of gender identities and practices within schools. These also reify sex-based relationships between men and women beyond schools. Hence, if gender based violence are 
learned and practices in schools it would definitely be practiced in larger society. Physical masculinity is expressed through forms of violence which does two things: firstly, self-regulation is ensured when a boy abides by the modality of masculinity and secondly, it is also strategy to exhibit one's power. This exhibition of power occurs both formally and informally, e.g. separate queues for boys and girls and/or appointment of males as class representatives. According to (Sandra Milligan, Thomson, \& Council, 1992), the very act of denial of the existence of sexual harassment - especially by boys and teachers - is testimony to the fact that the social structure of school is built around the notion of 'boys will always be boys'. Similarly, in their research on assessing students' perception of violence in the public schools, (Everett \& Price, 1995) found that $31 \%$ of the boys, $7 \%$ of girls, and $40 \%$ of ...' poor-grade-earners reported to have carried a weapon to school, at least once (Everett and Price, 1995). With respect to threatening a teacher, 10 percent of males and $20 \%$ of poor grade-earners reported to be involved in it (Everett and Price, 1995). In gender terms, the survey found that comparatively males were more often involved in crimes at their neighborhoods (Everett et al., 1995). Similarly, '[f]or most types of violence, males significantly more than females were likely to be victims'. The study also highlight the significance of pre-existing crime rates in an area as they found that in neighborhoods with high crime rate children experienced more violence (Everett and Price, 1995: 348). With respect to causes of violence, the study found that the following as reasons for violence by the respondents: gang or group membership (35\%), exposure to violence in the mass media (22\%), lack of parental supervision at home (35\%), and involvement with drugs or alcohol (24\%), as the four top-most contributing factors for violence (Evertt and Price, 1995).

Usually one of the organizing principles of school is compulsory heterosexuality. Through it the mapping of polarized positions occurs. This also helps in configuring gender and sexuality e.g. by criticizing, ridiculing, and ostracizing homosexual relations (Epstein \& Johnson, 1998). For Compulsory heterosexuality coupled with age/authority relationship between teachers and students strengthen and interact with gender/sexual regime. Besides teacher-student interaction, peer-pressure is also means for gender/sexual regulation in schools, especially with respect to constructing and perpetuating masculinity in schools (Skelton \& Francis, 2005). Bypassing one's gender role could be corrected with punishment, i.e. ridicule, ostracism, intimidation, verbal abuse etc. (Kehily \& Swann, 2003; Renold, 2002) For instance, across many cultures a girl who is outgoing, assertive and confident is usually referred to as promiscuous, which according to (Bhana, 2005) is a violent expression of masculinity. Similarly, if a girl rejects sexual advances, especially from teachers, she is harassed and humiliated. Sometimes, for girls, the only alternative to avoid physical punishment is to concede to sexual intercourse (Human Rights Watch, 2001). Some scholars use the terms hegemonic masculinity and emphasized femininity to describe the way media does gender (Robert William Connell, 1987) "Hegemonic masculinity today is a matter of the subordination of women, authority, aggression, and technical competence. Emphasized femininity is subordinate to and defined by hegemonic masculinity. [It is] organized around themes of dependence, sexual receptivity, and motherhood" (Cavender, Bond-Maupin, \& Jurik, 1999). Similarly, masculinity is often characterized as "tough, professional, public, outdoor, and strong, whereas femininity is sensitive, domestic, private, indoor, and weak" (Cuklanz, 2000). Messner (1992) explained how boys learn to define their gender identity: "Indeed, boys learn early that if it is difficult to define masculinity in terms of what it is, it is at least clear what it is not. A boy is not considered a masculine if he is feminine" (pp. 35-36) (Finley et. al., 2007).

According to Martin's (2001: 4) qualitative study on harassment in schools, harassment of boys occur just as frequently as it occurs to girls. Usually older boys harass younger ones. Young girls join harassers often as way of dealing with 'outsiders' like in-group and out-group feeling etc. (Mills, 2001). Martin (2001: 5) also found that teacher considered boys' sexual harassment of a 'slut' as normal. Moreover, if an incident of sexual harassment is reported, teachers first try to find out as what 'type' of girl has been harassed. Martin (2001) also confirmed the belief that teachers are themselves perpetrators of sexual harassment. In relation to the above, it should also be noted that teachers' differential use of disciplining strategies such as corporal punishment contributes towards reinforcement of gender identities (Antonowicz, 2010) and gender relations between boys and girls (Bisika, Ntata, \& Konyani, 2009). Teachers usually justify using corporal punishment with respect to boys under the rationale that it would make them tough (Morrell, 2002). In such an environment it is least unlikely that boys and girls get socialized about their sex-based roles according to the dictates of larger social structure. In addition to these demographic density and size of school as well as size 
of classrooms contribute towards violence. Schools often operate as factories where students are treated as products (Harber, 2002: 12). Resultantly, big-sized schools could lead to alienation from school and disconnection from education and drop-outs are high in big-sized schools (developed countries) (Meyer, 2010a, 2010b). It also introduces inadequacy in teachers' and managers' supervision of school environment (Plan, 2008: 39).

The issue of gender-based violence was raised by feminist activists during 1970s. Initially the focus of attention was the unwanted sexual attention that women faced in the workplace (V. E. Lee \& Burkam, 1996). The institutional setting of workplace was also the first site for research on sexual harassment (Vappu, Jenny, $\&$ Mervi, 2003). Soon the discussion on sexual harassment and other forms of gender-based violence broadened to include institution of education. The first cases of sexual harassment were filed in higher educational institutions but it was soon followed by analysis of primary and secondary schools (Lee et al., 1996: 384-385). During 1970s and 1980s feminists heavily relied on sex-role theory(McLellan, 2002), according to which children are socialized to view their roles in relation to their sex. Secondly, the theory also holds that, children are just passive recipients of knowledge regarding their sex-based roles. Finally, sex-role theory suffered from the assumption of treating girls and boys as homogeneous categories (McLellan, 2002). Later researches, for instance Connell (1987), refuted sex-role theory's claim that that girls and boys are homogenous categories and that they are not passive recipients of sex-appropriate knowledge (McLellan, 2002: 3). It is also pertinent to mention that the education settings in the North were the initial sites for such research (Leach, Kadzamira, \& Lemani, 2003).

According Gardner and his colleagues' research on schools in Jamaica, 'Girls, older children, those in higher grades, and those attending all age schools/junior high schools were more likely to know victims of violence or to consider child abuse, insults, or self-defense as violence' (Gardner et al., 2003: 101). The gender-based risk assessment of Gardner et al.'s (2003: 102) research demonstrate that male students felt more at risk of violence than female students. Similarly, in their research on assessing students' perception of violence in the public schools, Everett and Price (1995: 346-47) found that 31\% of the boys, $7 \%$ of girls, and $40 \%$ of poorgrade-earners reported to have carried a weapon to school, at least once (Everett and Price, 1995: 346-347). With respect to threatening a teacher, 10 percent of males and $20 \%$ of poor grade-earners reported to be involved in it (Everett and Price, 1995). In gender terms, the survey found that comparatively males were more often involved in crimes at their neighborhoods (Everett et al., 1995). Similarly, '[f]or most types of violence, males significantly more than females were likely to be victims'. The study also highlight the significance of pre-existing crime rates in an area as they found that in neighborhoods with high crime rate children experienced more violence (Everett and Price, 1995: 348). With respect to causes of violence, the study found that the following as reasons for violence by the respondents: gang or group membership (35\%), exposure to violence in the mass media (22\%), lack of parental supervision at home (35\%), and involvement with drugs or alcohol (24\%), as the four top-most contributing factors for violence (Evertt and Price, 1995). Based on the literature review, the following was designed for this study. The model shows the relationship between violent culture in schools with physical violence, socio-psychological violence, sexual violence and economic violence.

4.Methodology: The main purpose of this study was to investigate the causes of gender based violence in schools in KPK Pakistan. Using a survey design, a sample size of 522 respondents $(54.6 \%$ boys and $45.4 \%$ girls) was randomly selected on proportional allocation basis from Grade 10 students. Frequency and percentage distribution was carried out at uni-variate and bi-variate levels. Moreover, chi-square test was used to determine the level of association between variables (both independent and dependent). This study was confined to the gender based dynamics of violence in two selected districts of Khyber Pakhtunkhwa Province, Pakistan namely, Peshawar and Mardan. The focus was on the demographic profiles, reasons, social structure, gender order, social class and ethnic division and measures of school administration besides community to create violence free environment at schools. The data for this study was collected from two districts of Khyber Pakhtunkhwa province of Pakistan namely Peshawar and Mardan as mentioned earlier. Khyber Pakhtunkhwa province is located in North West of Pakistan at $160 \mathrm{~km}$ from federal Capital Islamabad. The data for this study was collected from two districts of Khyber Pakhtunkhwa province of Pakistan namely 
Peshawar and Mardan as mentioned earlier. Khyber Pakhtunkhwa province is located in North West of Pakistan at $160 \mathrm{~km}$ from federal Capital Islamabad.

5.Data Analysis: Data collected was scrutinized, edited and labeled with codes to make it ready for electrification. A soft data entry sheet was developed with the help of SPSS in a format given in its 16.0 version. The data after complete entry through the help of 3 data entry operators was examined through $10 \%$ verification of the total data set locating the missing punches or repeat entry or any other human error before apply statistical techniques or calculating results. Once the data set was ready on all standards, was put for analysis using statistical parameters namely, associational procedures (uni-variate and bi-variate).

5.1. Uni-variate Analysis: For all demographic information and analysis of gender based distribution of respondents for their socio-economic standing, uni-variate analyses were carried out. For this section frequency distribution, percentages of the respondents and chi-square were used to monitor association pattern of these demographic indicators with gender of the respondents.

5.2. Bi-variate Analysis: Test of Association (Bi-variate analyses) were carried out to study the association amongst dependent and independent variables. This type of analyses has shown the trend of the responses favoring or opposing one or other aspect of the variables under enquiry. McCall (1975) outlined the procedure for the Suppositions formulated to work out such type of association between the independent and dependent variables examined through chi-square(Sprinthall \& Fisk, 1990).

$$
\chi_{o b s}^{2}=\sum_{j=1}^{r} \sum_{k=1}^{c} \frac{\left(O_{j k}-\mathrm{E}_{\mathrm{jk}}\right)^{2}}{\mathrm{E}_{\mathrm{jk}}}
$$

Where "Ojk" was the observed frequency in the data corresponding to the intersection of the $\mathrm{j}$-th row and k-th column, "Ejk" the expected frequency in the cell corresponding to the intersection of the $\mathrm{j}$-th row and k-th column, " $r$ " the number of rows and "c" the number of columns. The expression in (I) is distributed as chisquare with relevant degrees of freedom, calculated as follows; $\mathrm{Df}=(\mathrm{r}-1)(\mathrm{c}-1)$. It is assumed that, the themes for each group are randomly and independently selected, the groups are independent, and each observation must qualify for one and only one category(Sprinthall \& Fisk, 1990). In addition, the sample size must objectively be large such that no predictable frequency is less than 5 , for $\mathrm{r}$ and $\mathrm{c}>2$, or $<10 \mathrm{if} \mathrm{r}=\mathrm{c}=2$. However, this supposition was dishonored several times in the data and therefore, Fisher Exact Test (also known as exact chi-square test) was used as an alternative of simple chi- square. The relationship developed by Fisher is given in equation-II (Rhoades \& Overall, 1982)

FisherExad Test Probability $=\frac{(\mathrm{a}+\mathrm{b}) !(\mathrm{c}+\mathrm{d}) !(\mathrm{a}+\mathrm{c}) !(\mathrm{b}+\mathrm{d}) !}{N ! \mathrm{a} ! \mathrm{b} ! \mathrm{c} ! \mathrm{d} !}$

Where $a, b, c$ and $d$ were the observed numbers in four cells of contingency table and " $n$ " the total number of observations.

Table 1: Gender-based Distribution of Government and Private High Schools in Selected Districts

\begin{tabular}{|l|l|l|l|l|l|l|}
\hline \multirow{2}{*}{ Gender } & Peshawar* & \multicolumn{5}{|l|}{ Mardan** } \\
\cline { 2 - 7 } & Government & Private & Total & Government & Private & Total \\
\hline Boys & 103 & 329 & 432 & 85 & 122 & 207 \\
\hline Girls & 50 & 232 & 282 & 50 & 82 & 132 \\
\hline Total & 153 & 561 & 714 & 135 & 204 & 339 \\
\hline
\end{tabular}

Sources: *Result Gazette: Secondary School Certificate 9th, 2012 Annual, Board of Intermediate and Secondary Education, Peshawar. Khyber Pakhtunkhwa 
As table 1 shows in District Peshawar the total 29340 students study at 714 Schools, out of them 432 schools for boys and 282 are girls' schools. Out of these total 714 schools 561 are private schools and 153 are government Schools. In District Peshawar the average number of students per school is thus 41.09 however if it is divided on single variable i.e. public and private; 82.41 students per school is in government sector and 29.82 in private sector Schools. In District Mardan a total of 20006 students observed study at 339 Schools. Out of them 207 schools are for boys and 132 are for girls. Total private schools are 204 and 135 government Schools. In District Mardan the average number of students per school is 59.01 however, if it is separated 115.11 average students per school in government sector and 21.85 in private sector.

\subsection{Gender of the respondents}

Table 1: Frequency and percentage distribution on the basis Gender

\begin{tabular}{lll}
\hline Gender & Frequency & Percent \\
\hline Male & 285 & 54.6 \\
\hline Female & 237 & 45.4 \\
\hline Total & 522 & 100.0 \\
\hline
\end{tabular}

Source: Field Data

Frequency and percentage distribution of respondents with respect to their gender is given in Table 2 . The result shows that a high proportion of $54.6 \%$ respondents were male and $45.4 \%$ respondents were female. Gender is an important background variable and has cultural significance, specifically in determining violence at School among Students. It is perhaps the prevailing cultural endorsement for attainment towards education being considered as binding upon all human beings irrespective of gender considerations. It is only possible through an institutionalized way as its apparent status is closely revealed by the above findings. Institutional roles are the primary basis for the development of institutional traditions and formal norms which leads to the emergence of a regime with the capacity of participating of both the genders (Dunne et al., 2006; Kessler \& McKenna, 1985).

\subsection{Frequency and Percentage Distribution of Respondents on the basis of Age}

\begin{tabular}{lllll}
\multirow{2}{*}{ Gender } & Statistics & \multicolumn{3}{c}{ Age of Respondents } \\
\cline { 3 - 5 } & & 15 and below & 16 years & 17 and above \\
\hline \multirow{2}{*}{ Male } & Cases & 99 & 154 & 32 \\
\hline \multirow{2}{*}{ Female } & Percent & 18.97 & 29.5 & 6.13 \\
\hline \multirow{2}{*}{ Total } & Cases & 92 & 125 & 20 \\
& Percent & 17.6 & 23.95 & 3.83 \\
\hline
\end{tabular}

Chi-Square 1.640 (0.440) Source: Field Data

Age group distribution of respondents is given in Table 1. Majority of $53.45 \%$ respondents were of 16 years followed by $36.6 \%$ students having aged 15 or below at the time of data collection. A reasonable number of students $9.96 \%$ were aged 17 and above most of them $6.13 \%$ were male students. 


\subsection{Status of Students in Present Grade (10)}

When did you Join Grade 10

\begin{tabular}{|c|c|c|c|}
\hline Gender & Statistics & Fresh student & Repeated \\
\hline \multirow{3}{*}{ Male } & Cases & 267 & 18 \\
\hline & Percent & 51.15 & 3.45 \\
\hline & Cases & 232 & 5 \\
\hline \multirow[t]{2}{*}{ Female } & Percent & 44.45 & 0.96 \\
\hline & Cases & 499 & 23 \\
\hline Total & Percent & 95.59 & 4.41 \\
\hline
\end{tabular}

Chi-Square 8.018 (0.018) Source: Field Data

Distribution of respondents on the basis of their joining in grade 10 is given in table 2 shows that a high majority of $95.59 \%$ respondents were fresh students and $4.41 \%$ were repeated students of grade 10 . Relationship between the Joining grade 10 as fresh or repeater at school was found significant $(p=0.018)$ with gender based distribution of respondents.

5.6 Gender Based Distribution of Respondents in Public/Private Schools.

Table No.3 Gender Based Distribution of Respondents in Public/Private Schools

\begin{tabular}{lllll}
\hline Gender & Statistics & \multicolumn{3}{l}{ Status of School (Government/Private) } \\
\cline { 3 - 5 } & & Private & Public & Total \\
\hline \multirow{3}{*}{ Male } & Cases & 145 & 140 & 285 \\
\hline \multirow{3}{*}{ Female } & Percent & 27.78 & 26.82 & 54.6 \\
\hline & Cases & 125 & 112 & 237 \\
Total & Percent & 23.95 & 21.45 & 45.4 \\
\hline
\end{tabular}

Chi-Square 0.0180 (0.725) Source: Field Data

Distribution of respondents in Public/Private Schools is given in Table 3. A high majority of 51.72\% respondents represents private schools in the study with remaining 48.27 as having representation of Public Sector Schools. However in both public and private majority of respondents picked up as parts of the sample were male representing (145students) $27.78 \%$ and (140 students) $26.82 \%$ in Private and Public Schools respectively out of the total 522 respondents

\section{Findings and Discussion}

Analysis of Students' attitude towards Family Role in Violence at School

\begin{tabular}{rcrrrrr} 
& \multicolumn{3}{c}{ Students Consult Family in Matters of School Violence } \\
\hline \multirow{2}{*}{ Gender } & Statistics & Agree & Disagree & Don't Know & Total \\
& & & & & \\
\hline & Cases & 24 & 239 & 22 & 285 \\
Male & Percent & 4.6 & 45.78 & 4.21 & 54.6 \\
\hline \multirow{2}{*}{ Female } & \multirow{2}{*}{ Cases } & 43 & 168 & 26 & 237 \\
\hline
\end{tabular}




\begin{tabular}{rrrrrr} 
& Percent & 8.24 & 32.18 & 4.98 & 45.4 \\
\hline & Cases & 67 & 407 & 48 & 522 \\
Total & Percent & 12.83 & 77.97 & 9.19 & 100 \\
\hline
\end{tabular}

Chi-Square 13.810 (0.001) Source: Field Data

A majority of $77.97 \%$ respondents did not consult or inform their family if they were punished physically by teacher, $45.78 \%$ of them were boys and $32.12 \%$ were girls. Only $12.83 \%$ students shared that they consult their respective families if they are exposed to violence at schools both from teachers, students or peers. Of them who said they consult families in incidence of violence at school, $4.6 \%$ were boys and remaining majority $8.24 \%$ of them were girls. Obvious results could be detected from the above statements that although punishment is around at school but intimating it to parents are not prevalent. It is probably due to the teacher's authority who consider while exercising it as legitimate. This is in line to the Jackson (2003) finding that students behavior is often controlled through the process of reward and punishment. Corporal punishment is also believed to be an outcome factor of reinforcement of gender identities upon its relationship (Antonowicz, 2010). The above statistics were drawn from responses to statements asked on Likert scale if students share physical aggression of teachers, peers at school or if they don't like a particular teacher for his behavior. The gender based analysis of students consultation with family in matters of school violence shows to be highly significant $(\mathrm{p}=0.001)$. None sharing of the problems students face at school particularly male students could also be associated with gender role perceptions wherein amongst Pakhtun in a particular and in Pakistan in general like many other parts of the world, the concept of shame is associated with punishment if you are a receiver of it and boys have to avoid it in public.

Family Shows Interest in Issues of School Violence

\begin{tabular}{cccccc}
\hline Gender & Statistics & Agree & Disagree & Don't Know & Total \\
& & & & & \\
\hline \multirow{2}{*}{ Male } & Cases & 42 & 223 & 20 & 285 \\
& Percent & 8.04 & 42.72 & 3.83 & 54.6 \\
\hline Female & Cases & 24 & 191 & 22 & 237 \\
& Percent & 4.6 & 36.59 & 4.21 & 45.4 \\
Total & Cases & 66 & 414 & 42 & 522 \\
\hline
\end{tabular}

Chi-Square 3.090 (0.213) Source: Field Data

The respondents were inquired herein about their perception if families inquired for reasons of child punishment or any other form of violence if so happened at schools. The statements for this sub-variable included i.e. family ask for reasons of punishment, consult teachers if child punished and console child if get into fear of classmates or encourage to retaliate bullying if happens at schools. The respondents were also enquired about their parents' interest and care for them in selection of their friends' age and nature of relationship/association they have. The responses shows that gender of respondent could not establish significant relation with family interest in child's reception of violence at school $(p=0.213)$. The table (5.2.3.2) shows that $79.31 \%$ students informed that their families didn't took these events seriously, $42.72 \%$ of them were male and $36.59 \%$ were female. $12.64 \%$ respondents agreed to the statement that their families shown interests in issue of school violence among them $8.04 \%$ were male and $4.6 \%$ were female respondents. The remaining $8.04 \%$ were hesitant to respond. This could be due to a faith of trust on school management considering them as reformative body towards reconstruction of the evil thinking and deeds of students. It is either a high level of awareness amongst parents about the kids company or a close intimacy of the parents with the school management appraising them about the kid's involvement at the school. Schools occupy a central position in light of development towards children role transformation (Sullivan and Bash, 1967). 
Friends/Peers are more important than Family for Consultation in Violence

\begin{tabular}{cccccc}
\hline Gender & Statistics & Agree & Disagree & Don't Know & Total \\
& & & & & 285 \\
Male & Cases & 171 & 79 & 35 & 54.6 \\
\hline \multirow{2}{*}{ Female } & Percent & 32.76 & 15.13 & 6.7 & 237 \\
\hline \multirow{2}{*}{ Total } & Cases & 161 & 61 & 15 & 45.4 \\
\hline
\end{tabular}

Chi-Square 6.255 (0.044) Source: Field Data

However, friends/peers were more important than family for $63.6 \%$ respondents. This was inquired through statements like i.e. do you agree that friends/peers are more concerned than family if get hurt at schools, and I share all my personal problems with friends and not family. The gender based association of the variable was reasonably significant $(\mathrm{p}=0.044)$. However if we look at the percentages, $32.76 \%$ in agreement were male and $30.84 \%$ female. There were $26.82 \%$ those who were in disagreement to the statement that friends/peers are more important than family and amongst them $15.13 \%$ were male and were $11.68 \%$ female. Here too $9.58 \%$ were reluctant or did not know or shared their opinion on the subject. The appropriate cultural prerogatives help the pupil in identifying the suitable friends which is also being encouraged by the relevant families. However, these findings are in contrast to the De Wet (De Wet, 2007) and Plan (2008) which claims that in most Asian Countries violence is passed on as socialization to the schooling phenomenon.

7. Conlusion: The main purpose of this study to investigate into the dynamics of gender based violence in Pakistani Schools taking selected schools of Khyber Pakhtunkhwa as a case study. The study was designed with a conceptual framework of independent variable namely attitude of student towards family role in violence at school with dependent variable School Related Gender Based Dynamics of Violence, The effects of these independent variables were investigated upon the dependent variable (gender based violence). The study further disclosed a link of schools and families in the existence of sexual violence pertaining to students. The concept of punishment and socialization at school having lifelong effects is the most contested issue in violence discourse. Besides learning, the child receives his social role and status here. In order to lead a productive life the child is trained into dos and don'ts of the prevalent culture or a society but this been remained the primary task of family institution both have to coordinate to get the most fruitful output for the society. The social controlling mechanisms inside school in form of sanctions help to mold and predict child's behavior but at the same time if family not remain in loop, may result in child suffer of physical, social or psychologically. School if single out to deal with students may risk of harm student's personality for the rest of his or her life. Punishment at school is perceived among adolescents (aged 14-18) as an internal age group issue and normal school culture, which is reinforced through peer pressure. This is believed not to be shared with family to remain and give posture of being grown boys and girls. To control those who may deviate by involving family or school administration in such matters, peers may intervene resultantly having another manifestation of violence at schools.

\section{REFERENCES}

[1] Antonowicz, L. (2010). Too often in silence: A report on school-based violence in West and Central Africa. UNICEF, Plan West Africa, Save the Children Sweden West Africa and ActionAid.

[2] Astor, R. A., Benbenishty, R., \& Estrada, J. N. (2009). School violence and theoretically atypical schools: The principal's centrality in orchestrating safe schools. American Educational Research Journal, 46(2), 423-461.

[3] Altbach, P. G., \& Kelly, G. P. (1978). Education and colonialism: Longman New York.

[4] Baker, J. E., \& Myles, B. S. (2003). Social skills training for children and adolescents with Asperger syndrome and social-communication problems: Autism Asperger Pub. 
[5] Bazan, C. (2009). Plan' Global Campaign To END VIOLENCE IN SCHOOLS. Woking, UK: Plan International. (Plan o. Document Number)

[6] Bhana, D. (2005). Violence and the gendered negotiation of masculinity among young black school boys in South Africa. African Masculinities. New York: Palgrave Macmillan.

[7] Bisika, T., Ntata, P., \& Konyani, S. (2009). Gender-violence and education in Malawi: a study of violence against girls as an obstruction to universal primary school education. Journal of Gender Studies, 18(3), 287294.

[8] Breivik, K., Olweus, D., \& Endresen, I. (2009). Does the quality of parentâ€"child relationships mediate the increased risk for antisocial behavior and substance use among adolescents in single-mother and single-father families? Journal of Divorce \& Remarriage, 50(6), 400-426.

[9] Cavender, G., Bond-Maupin, L., \& Jurik, N. C. (1999). The construction of gender in reality crime TV. Gender \& Society, 13(5), 643-663.

[10] Chandras, K. V. (2001). Prevention Strategies. 105p.; Published annually. For the 2000 issue, see ED 456, 65.

[11] Connell, R. W. (1987). Gender and power: Society, the person and sexual politics: Polity Press Cambridge.

[12] Cuklanz, L. M. (2000). Rape on prime time: Television, masculinity, and sexual violence: University of Pennsylvania Press.

[13] Davies, L. (2004). Education and conflict: Complexity and chaos. London: Routledge.

[14] Dashiff, C., DiMicco, W., Myers, B., \& Sheppard, K. (2009). Poverty and adolescent mental health. Journal of Child and Adolescent Psychiatric Nursing, 22(1), 23-32.

[15] De Wet, C. (2007). Free State educators' perceptions and observations of learner-on-learner, learner-oneducator and educator-on-learner school violence. Education as Change, 11(1), 59-85.

[16] Diprose, R. (2008). "Where'your people from, girl": Belonging to Race, Gender, and Place Beneath Clouds. differences, 19(3), 28-58.

[17]Dillon, N. (2012). The Effect of School Community Setting on Children Living in Poverty: A Survey of School Social Workers.

[18] Dubet, F. (2003). Juvenile and Urban Violence. International handbook of violence research, Dordrecht, Kluwer Academic Publishers, 937-952.

[19] Dunne, M., Humphreys, S., \& Leach, F. (2006). Gender violence in schools in the developing world. Gender and Education, 18(1), 75-98.

[20] Durkheim, E. (1970). Suicide London: Routledge and Kegan Paul.

[21] Epstein, D., \& Johnson, R. (1998). Schooling sexualities: Open University Press Buckingham.

[22] Evans, S. E., Davies, C., \& DiLillo, D. (2008). Exposure to domestic violence: A meta-analysis of child and adolescent outcomes. Aggression and Violent Behavior, 13(2), 131-140.

[23] Eacute, J., \& Esteve, M. (2000). The transformation of the teachers' role at the end of the twentieth century: New challenges for the future. Educational Review, 52(2), 197-207.

[24] Esteve, J. M. (2000). at the End of the Twentieth Century. Educational Review, 52(2).

[25] Everett, S. A., \& Price, J. H. (1995). Students' perceptions of violence in the public schools: the MetLife survey. Journal of Adolescent Health, 17(6), 345-352.

[26] Fry, P. S., \& Debats, D. L. (2010). Sources of human life-strengths, resilience, and health. New frontiers in resilient aging: Life-strengths and well-being in late life, 15-59.

[27] Garver, N. (1968). What violence is. The Nation, 209(24), 819-822.

[28] George, E. (2004). Instructions in Inequality: Development, Human Rights, Capabilities, and Gender Violence in Schools. Mich. J. Int'l L., 26, 1139.

[29] Gurr, T. R. (1979). On the history of violent crime in Europe and America. Beverly Hills: Sage Publications,

[30] Grosvenor, I., Lawn, M., \& Rousmaniere, K. (2000). Imaging past schooling: the necessity for montage. The Review of Education/Pedagogy/Cultural studies, 22(1), 71-85.

[31] Harber, C. (1998). Markets, equity and democracy'structural adjustment and the tensions of educational change in South Africa. International Journal of Educational Development, 18(3), 247-254.

[32] Harber, C. (2002). Schooling as Violence: An exploratory overview. Educational Review, 54(1), 7-16.

[33] Holmes, J. (1993). Attachment theory: a biological basis for psychotherapy? The British Journal of Psychiatry, 163(4), 430-438.

[34] Human Rights, W. (2001). Unequal Protection: the state response to violent crime on South African farms: Human Rights Watch.

[35] Jackson, R. A., \& Newman, M. A. (2004). Sexual harassment in the federal workplace revisited: Influences on sexual harassment by gender. Public Administration Review, 64(6), 705-717. 
[36] Karstedt, S., \& Eisner, M. (2009). Introduction: Is a General Theory of Violence Possible? International Journal of Conflict and Violence, 3(1), 4-8.

[37] Kehily, M. J., \& Swann, J. (2003). Children's cultural worlds (Vol. 3): John Wiley in association with the Open University.

[38] Kenway, J., \& Fitzclarence, L. (1997). Masculinity, violence and schooling: challenging'poisonous pedagogies'. Gender and Education, 9(1), 117-134.

[39] Kessler, S. J., \& McKenna, W. (1985). Gender: An ethnomethodological approach: University of Chicago Press.

[40] Kilpatrick, D. G., Acierno, R., Saunders, B., Resnick, H. S., Best, C. L., \& Schnurr, P. P. (2000). Risk factors for adolescent substance abuse and dependence: data from a national sample. Journal of consulting and clinical psychology, 68(1), 19.

[41] Kim, J. H., \& McGee Bailey, S. (2003). Unsafe Schools: A Literature Review of School-Related GenderBased Violence in Developing Countries. Washington DC: USAID. Available at: http://www.USAid.gov/our_work/cross-cutting_programs/wid/pubs/unsafe_schools_literature_review. pdf In the Painful lessons report.

[42] Koch, J., \& Irby, B. J. (2005). Gender and schooling in the early years: Information Age Pub Incorporated.

[43] Lovegrove, P. J., Henry, K. L., \& Slater, M. D. (2012). Examination of the predictors of latent class typologies of bullying involvement among middle school students. Journal of School Violence, 11(1), 75-93.

[44] Mallet, P., \& Paty, B. (1999). How French counsellors treat school violence: An adult-centered approach. International Journal for the Advancement of Counselling, 21(4), 279-300.

[45] Meyer, E. J. (2010a). Gender and sexual diversity in schools (Vol. 10): Springer.

[46] Meyer, E. J. (2010b). Introduction: Why Learn About Gender and Sexual Diversity in Schools? In Gender and Sexual Diversity in Schools (pp. 3-26): Springer.

[47] Milligan, S., Thomson, K., \& Council, A. E. (1992). Listening to Girls: A Report of the Consultancy Undertaken for the Review of the National Policy for the Education for Girls, Conducted by the Australian Education Council, 1991: Asherden \& Associates [for the Australian Education Council's Committee to Review the National Policy for the Education of Girls in Australian Schools].

[48] Mills, M. (2001). Challenging violence in schools: Open University Press Buckingham.

[49] Moffitt, T. E. (1993). Adolescence-limited and life-course-persistent antisocial behavior: a developmental taxonomy. Psychological review, 100(4), 674.

[50] Morrell, R. (2002). Men, movements, and gender transformation in South Africa. The Journal of Men's Studies, 10(3), 309-327.

[51] Morrison, A., \& Orlando, M. B. (2004). The costs and impacts of gender-based violence in developing countries: Methodological considerations and new evidence. Retrieved March, 5, 2007.

[52] Muehlenhard, C. L., Harney, P. A., \& Jones, J. M. (1992). From 'victim-precipitated rap- to-date rap': How far have we come? Annual Review of Sex Research, 3(1), 219-253.

[53] Mynard, H., Joseph, S., \& Alexander, J. (2000). Peer-victimisation and posttraumatic stress in adolescents. Personality and Individual Differences, 29(5), 815-821.

[54] Naz, A., Khan, W., Daraz, U., Hussain, M., \& Khan, Q. (2011). The Impacts of Corporal Punishment on Students Academic Performance/Career and Personality Development Up-To Secondary Level Education in Khyber Pakhtunkhwa Pakistan. International Journal of Business and Social Science, 2(12).

[55] Neubarth, F., \& Rennison, J. R. (1999). An x-bar theory of Government Phonology. Ms., University of Vienna.

[56] Ngakane, M. V., Muthukrishna, N., \& Ngcobo, J. E. (2012). Experiencing Violence in Schools: Voices of Learners in the Lesotho Context. Anthropologist, 14(1), 39-48.

[57] Ngale, I. F. (2009). Family structure and juvenile delinquency [Electronic Version]. Internet Journal of Criminology, from www.internetjournalofcriminology.com

[58] Parker, R., Barbosa, R. M., \& Aggleton, P. (2000). Framing the sexual subject: the politics of gender, sexuality, and power. Berkeley: CA: University of California Press.

[59] Piotrowski, D., \& Hoot, J. (2008). Bullying and violence in schools: What teachers should know and do. Childhood Education, 84(6), 357-363.

[60] Renold, E. (2002). Presumed Innocence (Hetero) Sexual, Heterosexist and Homophobic Harassment among Primary School Girls and Boys. Childhood, 9(4), 415-434.

[61] SAHIL. (2008). Cruel numbers 2008: Letting you know the reality [Electronic Version]. Cruel Number,

[62] Salmi, V., Smolej, M., \& Kivivuori, J. (2007). Crime victimization, exposure to crime news and social trust 
among adolescents. Young, 15(3), 255-272.

[63] Secretariat, C. (2002). Gender mainstreaming in HIV/AIDS: Taking a multisectoral approach: Commonwealth Secretariat.

[64] Skelton, C., \& Francis, B. (2005). A feminist critique of education: 15 years of gender education: Routledge Falmer.

[65] Sen, A. (1999). Critical Reflection. Health and Development. Bulletin of the World Health Organization, $77(8)$.

[66] SPARC. (2004). State of Children in Pakistan. Islamabad: SPARC. (SPARC o. Document Number)

[67] SPARC. (2009). State of Children in Pakistan. Islamabad, Pakistan: SPARCo. Document Number)

[68] Sprinthall, R. C., \& Fisk, S. T. (1990). Basic statistical analysis: Prentice Hall Englewood Cliffs, NJ.

[69] Stromquist, N. P. (2007). Internationalization as a response to globalization: Radical shifts in university environments. Higher Education, 53(1), 81-105.

[70] Sullivan, C., \& Bash, S. (1967). Current programs for delinquency prevention. Delinquency Prevention: Theory and Practice, 51-72.

[71] Tamutiene, I. (2008). School violence: experiences of absentee students. Journal of School Violence, 7(1), $115-130$.

[72] Tunley, R. (1962). Kids, crime and chaos: Harper \& Row

[73] Unterhalter, E. (2003). Crossing Disciplinary Boundaries: the potential of Sen's capability approach for sociologists of education. British Journal of Sociology of Education, 24(5), 665-669.

[74] Vance, C. S. (1984). Pleasure and danger: Exploring female sexuality: Routledge \& Kegan Paul Books.

[75] Vetten, L., \& Bhana, K. (2001). Violence, vengeance and gender: a preliminary investigation into the links between HIV/AIDS and violence against women in South Africa. Johannesburg, The Centre for the Study of Violence \& Reconciliation.

[76] Watts, C., \& Zimmerman, C. (2002). Violence against women: global scope and magnitude. The lancet, 359(9313), 1232-1237.

[77] White, L. A. (1949). The science of culture: A study of man and civilization: Grove Press New York.

[78] Windham, C. (2005). The student's perspective: Educause.

[79] Yusuf, M. (2009). Prospects of Youth Radicalization in Pakistan: Implications for US Policy

[80] Yerin-Guneri, O., Erdur Baker, O., \& Akbaba Altun, S. (2006). School violence among urban Turkish students: A qualitative investigation. Paper presented at the European Conference on Educational Research. 